\title{
Anticoagulation in sub-Saharan Africa: Are Direct Oral Anticoagulants the answer? A review of lessons learnt from warfarin
}

\author{
Jerome Semakula ${ }^{1}$, Geraldine Kisa ${ }^{1}$, Johannes Mouton ${ }^{2}$, Karen Cohen ${ }^{3}$, Marc Blockman ${ }^{2}$, \\ Munir Pirmohamed ${ }^{4}$, Christine Sekaggya-Wiltshire ${ }^{1}$, and Catriona Waitt ${ }^{4}$ \\ ${ }^{1}$ Makerere University College of Health Sciences \\ ${ }^{2}$ University of Cape Town \\ ${ }^{3}$ Division of Clinical Pharmacology, Department of Medicine, University of Cape Town, \\ Cape Town, South Africa. \\ ${ }^{4}$ University of Liverpool Institute of Translational Medicine
}

November 9, 2020

\begin{abstract}
Warfarin has existed for more than seven decades and has been the anticoagulant of choice for many thromboembolic disorders. The recent introduction of direct acting oral anticoagulants (DOACs) has however caused a shift in preference by healthcare professionals all over the world. DOACs have been found to be at least as effective as warfarin in prevention of stroke in patients with atrial fibrillation and in treatment of venous thromboembolism. In sub-Saharan Africa, however, the widespread use of DOACs has been hampered mainly by their higher acquisition costs. As the drugs come off patent, their use in sub-Saharan Africa is likely to increase. However, very few trials have been conducted in African settings, and safety concerns will need to be addressed with further study before widespread adoption into clinical practice.
\end{abstract}

\section{Hosted file}

Anticoagulation in SSA_Are DOACs the answer_BJCP.pdf available at https://authorea.com/ users/347143/articles/491893-anticoagulation-in-sub-saharan-africa-are-direct-oralanticoagulants-the-answer-a-review-of-lessons-learnt-from-warfarin 